PART I

AQUEOUS ALTERATION OF CARBONACEOUS CHONDRITE

PARENT BODIES - INSIGHTS FROM CARBONATE CLUMPED ISOTOPE THEMOMETRY 
Chapter 1

\title{
TEMPERATURES OF AQUEOUS ALTERATION AND EVIDENCE FOR METHANE GENERATION ON THE PARENT BODIES OF THE CM CHONDRITES
}

Weifu Guo and John M. Eiler

\author{
Division of Geological and Planetary Sciences, \\ California Institute of Technology, Pasadena, CA 91125
}

(Published in Geochimica et Cosmochimica Acta, 71, 5565-5575, 2007) 


\begin{abstract}
Aqueous alteration of primitive meteorites was among the earliest geological process during the evolution of our solar system. 'Clumped-isotope' thermometry of carbonates in the CM chondrites Cold Bokkeveld, Murray, and Murchison, demonstrates that they underwent aqueous alteration at $20-71^{\circ} \mathrm{C}$ from a fluid with $\delta^{18} \mathrm{O}_{\text {Vsmow }}$ of 1.8 to $7.8 \%$ and $\delta^{17} \mathrm{O}_{\text {VSMOW }}$ of -0.2 to $2.9 \%$. The $\delta^{13} \mathrm{C}_{\mathrm{PDB}}$ values of these carbonates exhibit a negative correlation with the $\delta^{18} \mathrm{O}$ of their formation waters, consistent with formation and escape of ${ }^{13} \mathrm{C}$-depleted $\mathrm{CH}_{4}$ during aqueous alteration. Methane generation under these conditions implies that the alteration fluid was characterized by an Eh $\leq-0.67$ and $\mathrm{pH} \geq 12.5$ (or lower at the highest alteration temperatures). Our findings suggest that that methane generation may have been a widespread consequence of planetesimal and planetary aqueous alteration, perhaps explaining the occurrence of methane on Titan, Triton, Pluto and Kuiper-belt objects.
\end{abstract}

\title{
1. INTRODUCTION
}

Aqueous alteration occurred on the parent bodies of the carbonaceous chondrites within the first tens of million of years of solar system history (Endress et al., 1996). The conditions of these processes are poorly constrained, both because direct samples of reactant fluids are rarely, if ever, preserved (Zolensky et al., 2004), and because the altered solids consist of complex, fine-grained mixtures of phases that presents challenges to equilibrium thermodynamic approaches to calculating temperature, oxygen fugacity and other relevant variables. Previous estimates of the temperatures of $\mathrm{CM}$ chondrite alteration range from $\angle 20^{\circ} \mathrm{C}$ to $<170^{\circ} \mathrm{C}$ (Keil, 2000), based on the stabilities of 
constituent phases (e.g. tochilinite; Zolenksy, 1984) or oxygen isotope fractionations between carbonate and phyllosilicate in the matrix (Clayton and Mayeda, 1984). This first approach yields only upper temperature limits; the second is only valid if matrix carbonate and phyllosilicate achieved oxygen-isotope exchange equilibrium. Differences in $\Delta^{17} \mathrm{O}$ between carbonate and matrix in these samples (Benedix et al., 2003) indicate this assumption is not valid. In any event, uncertainties regarding the reduced partition coefficient ratios of the relevant phyllosilicate phases (Sheppard and Gilg, 1996) engender large uncertainties in apparent temperatures based on this approach. Baker et al. (2002) recently determined the oxygen isotopic composition of the structurally bound water released from phyllosilicates in Murchison and suggested an alteration temperature of $\sim 80^{\circ} \mathrm{C}$ for the $\mathrm{CM}$ chondrites based on the oxygen isotopic fractionation between this water and matrix carbonate. However, this estimation also assumes mutual isotopic equilibrium between these two reservoirs of oxygen.

We used the 'carbonate clumped-isotope thermometer' (Ghosh et al., 2006; Schauble et al., 2006) to determine the temperatures of carbonate precipitation in the CM chondrites. The carbonate clumped-isotope thermometer is based on a thermodynamic equilibrium that orders ${ }^{13} \mathrm{C}$ and ${ }^{18} \mathrm{O}$ into bonds with each other within the carbonate lattice, and is independent of the isotopic composition of any co-existing phase. Moreover, this temperature information, combined with the known temperaturedependence of carbonate-water oxygen isotope fractionation (Kim and O'Neil, 1997), allows us to determine the oxygen isotope compositions of waters from which these carbonates grew. 


\section{SAMPleS AND MeTHOd}

\subsection{Samples}

Carbonate in the CM chondrites is mostly calcite - the basis of previous calibrations of the carbonate clumped isotope thermometer (Ghosh et al., 2006; Ghosh et al., 2007) and is relatively homogeneous in composition and texture (Brearley and Jones, 1998). We analyzed carbonates from 7 splits of three different CM chondrites: Cold Bokkeveld (3 splits), Murray (1 split) and Murchison (3 splits). Each split was prepared from a separate fragment of a whole rock meteorite sample and ground individually. These samples represent near-extremes to the range of extent of aqueous alteration of $\mathrm{CM}$ chondrites: Murchison and Murray retain ca. $\sim 93 \%$ and $\sim 87 \%$, respectively, of their original coarse, anhydrous silicate (chondrules and CAIs), whereas Cold Bokkeveld retains only $\sim 45 \%$ of this original coarse anhydrous material (i.e., its texture more closely approaches that of the CI chondrites) (Browning et al., 1996).

\subsection{Carbonate clumped isotope thermometry}

${ }^{13} \mathrm{C}$ and ${ }^{18} \mathrm{O}$ in thermodynamically equilibrated carbonate minerals preferentially group or 'clump' together into the same carbonate ion group to form ${ }^{13} \mathrm{C}^{18} \mathrm{O}^{16} \mathrm{O}^{16} \mathrm{O}^{2-}$ as opposed to being randomly dispersed. This preferential clumping can be expressed through the equilibrium constant for the exchange reaction, ${ }^{13} \mathrm{C}^{16} \mathrm{O}^{16} \mathrm{O}^{16} \mathrm{O}^{2-}+$ ${ }^{12} \mathrm{C}^{18} \mathrm{O}^{16} \mathrm{O}^{16} \mathrm{O}^{2-}={ }^{13} \mathrm{C}^{18} \mathrm{O}^{16} \mathrm{O}^{16} \mathrm{O}^{2-}+{ }^{12} \mathrm{C}^{16} \mathrm{O}^{16} \mathrm{O}^{16} \mathrm{O}^{2-}$. Because the doubly-substituted isotopologue of the carbonate ion $\left({ }^{13} \mathrm{C}^{18} \mathrm{O}^{16} \mathrm{O}^{16} \mathrm{O}^{2-}\right)$ has a lower zero point energy than its normal and singly-substituted relatives $\left({ }^{12} \mathrm{C}^{16} \mathrm{O}^{16} \mathrm{O}^{16} \mathrm{O}^{2-}, \quad{ }^{13} \mathrm{C}^{16} \mathrm{O}^{16} \mathrm{O}^{16} \mathrm{O}^{2-}\right.$ and ${ }^{12} \mathrm{C}^{18} \mathrm{O}^{16} \mathrm{O}^{16} \mathrm{O}^{2-}$ ), the above reaction is thermodynamically driven to the right, producing 
abundances of ${ }^{13} \mathrm{C}^{18} \mathrm{O}^{16} \mathrm{O}^{16} \mathrm{O}^{2-}$ higher than that expected for a random distribution of isotopes. This abundance excess varies as a function of the temperature of carbonate growth or equilibration and forms the basis of a geothermometer (Ghosh et al., 2006; Schauble et al., 2006). The extent of ${ }^{13} \mathrm{C}-{ }^{18} \mathrm{O}$ clumping in a carbonate mineral is determined through the measurements of anomalous enrichment of mass $47 \mathrm{CO}_{2}$ (mainly ${ }^{13} \mathrm{C}^{18} \mathrm{O}^{16} \mathrm{O}$ ) in the $\mathrm{CO}_{2}$ derived from phosphoric acid digestion of that mineral (Ghosh et al., 2006). We define the mass 47 anomaly, $\Delta_{47}$, as the difference between the measured value of $\mathrm{R}^{47}$ (=[mass 47]/[mass 44]) and the value of $\mathrm{R}^{47}$ expected in that sample if its $\mathrm{C}$ and $\mathrm{O}$ isotopes are randomly distributed among all isotopologues: $\Delta_{47}=\left(\frac{\mathrm{R}_{\text {measrued }}^{47}}{\mathrm{R}_{\text {stochastic }}^{47}}-1\right) \times 1000$ (Eiler and Schauble, 2004; Affek and Eiler, 2006).

\subsection{Analytical method}

\subsubsection{Sample Digestion}

Each sample split consisted of a whole rock fragment weighing between 40 and 250 mg. Each split was ground to a grain size of $\leq 500 \mu \mathrm{m}$ with an agate mortar and pestle into unsieved particles and then reacted with anhydrous phosphoric acid at $25^{\circ} \mathrm{C}$ for 18 24 hours to extract $\mathrm{CO}_{2}$ from calcite. Carbonates other than calcite (e.g., dolomite) are rare in CM chondrites (Brearley and Jones, 1998) and do not react actively with phosphoric acid at $25^{\circ} \mathrm{C}$ (less than $20 \%$ reaction of dolomite within 24 hours, compared to $100 \%$ reaction of calcite; e.g., Al-Aasm et al., 1990). Therefore cross-contamination from other carbonate components in $\mathrm{CM}$ chondrite should be negligible during our extraction. 
We examined the contribution of $\mathrm{CO}_{2}$ from oxidation of organic matter by conducting stepped acid extractions at $25^{\circ} \mathrm{C}$ (i.e., anticipating that early steps would be dominated by carbonate and later steps by oxidation of organics). $\mathrm{CO}_{2}$ evolved at an average rate of $\sim 76.2 \mathrm{nmol} / \mathrm{mg} /$ day during the first 24 hours, and after that at an average rate of $\sim 0.9 \mathrm{nmol} / \mathrm{mg} /$ day, suggesting to us that $\mathrm{CO}_{2}$ extracted for the first 24 hours contained a negligible contribution from the oxidation of organic matter. We did not attempt to characterize the isotopic compositions of $\mathrm{CO}_{2}$ fractions collected after the first $24 \mathrm{hrs}$ in this study because their sizes were too small for $\Delta_{47}$ analysis and their $\delta^{13} \mathrm{C}$, $\delta^{18} \mathrm{O}$ and $\Delta^{17} \mathrm{O}$ values are well known from previous stepped-extraction studies (Grady et al., 1988; Benedix et al., 2003).

The yield of $\mathrm{CO}_{2}$ from each split varied between $39.3 \mu \mathrm{mol} / \mathrm{g}$ and $127.6 \mu \mathrm{mol} / \mathrm{g}$. We observe that smaller splits consistently produce higher yields of $\mathrm{CO}_{2}$ than larger splits (95.5-127.6 $\mu \mathrm{mol} / \mathrm{g}$ for 40.5-60.6 mg splits vs. 39.3-61.8 $\mu \mathrm{mol} / \mathrm{g}$ for 195.3-253.4 $\mathrm{mg}$ splits; Table 1). A similar correlation between $\mathrm{CO}_{2}$ yield and split size was observed in a previous study of CM chondrites (Murchison splits in Grady et al, 1988), and could be due to either heterogeneity among sample splits (i.e., if carbonate is generally present as widely-separated 'nuggets', smaller splits will produce greater maximum $\mathrm{CO}_{2}$ yields) or that phosphoric acid digestion more effectively attacks carbonate in smaller samples (e.g., if large amounts of ground sample are relatively impermeable). 


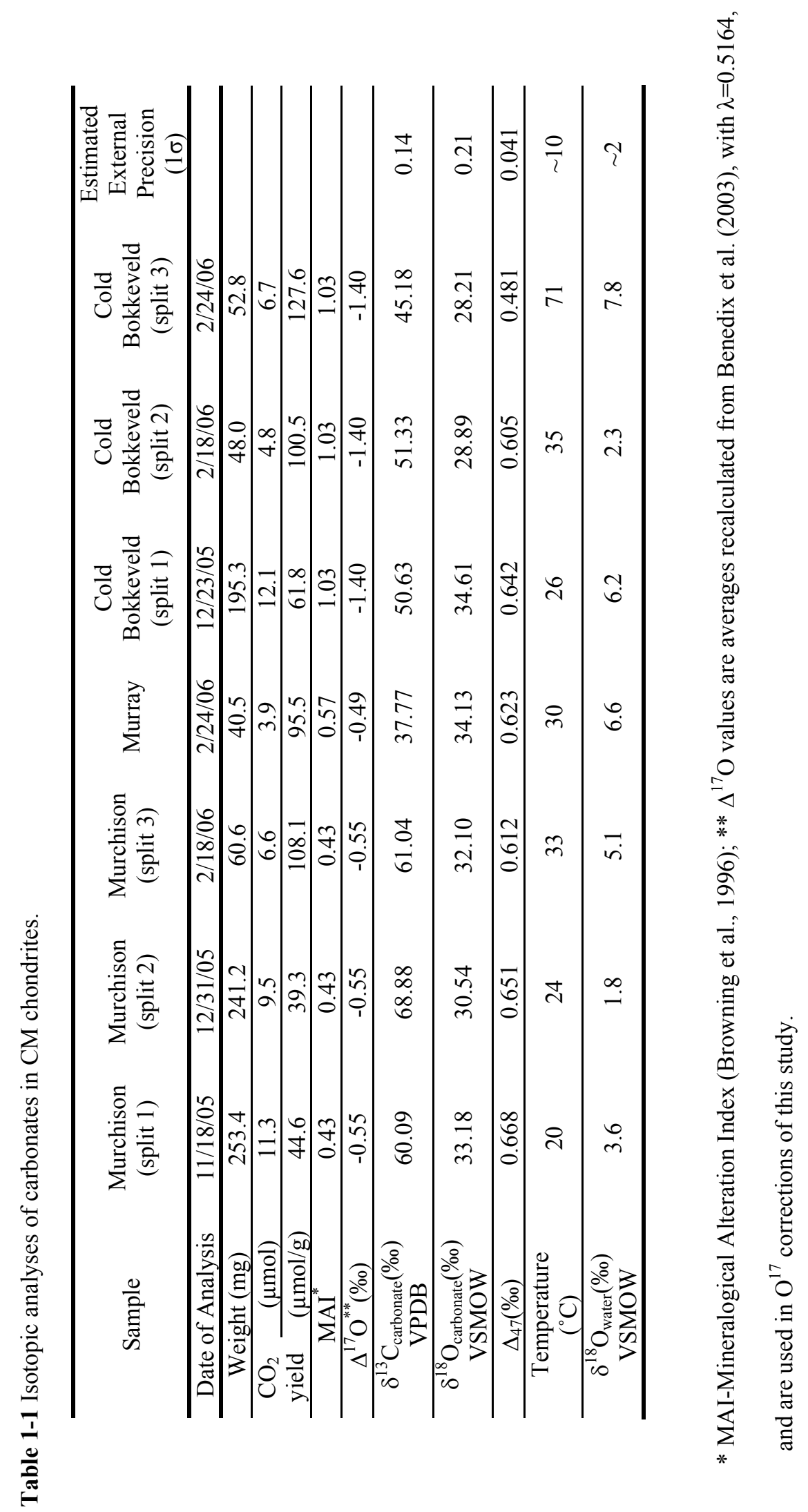


Because of the relatively low abundances of carbonates in $\mathrm{CM}$ chondrites and the precious nature of the samples, we generally obtained less $\mathrm{CO}_{2}$ from our samples $(\sim 5$ to $\sim 12 \mu \mathrm{mol}$ ) than analyzed in previous studies of the $\Delta_{47}$ of $\mathrm{CO}_{2}$ produced by acid digestion of carbonate $\left(\sim 50_{\mu} \mathrm{mol}\right.$; e.g., Ghosh et al., 2006).

\subsubsection{Purification of sample $\mathrm{CO}_{2}$}

$\mathrm{CO}_{2}$ produced by phosphoric acid digestion of $\mathrm{CM}$ chondrites is exceptionally rich in sulfur and organic contaminants that must be removed prior to isotopic analysis. Therefore, each sample of extracted $\mathrm{CO}_{2}$ was purified by exposure to dry $\mathrm{Ag}_{3} \mathrm{PO}_{4}$ (to remove sulfur contaminants, e.g., $\mathrm{H}_{2} \mathrm{~S}$ ), passage through a series of glass traps cooled with ethanol slush $\left(-78^{\circ} \mathrm{C}\right)$ and pentane slush $\left(-130^{\circ} \mathrm{C}\right)$, and passage through a Supelco Q-Plot GC column held at $-20^{\circ} \mathrm{C}$ (mainly to remove hydrocarbon contaminants; Affek and Eiler, 2006). Samples sized before and after dry $\mathrm{Ag}_{3} \mathrm{PO}_{4}$ treatment suggest that sulfur contaminants constitute $19-62 \%$ of the sample gas derived from phosphoric acid digestion of $\mathrm{CM}$ chondrite splits (38-62\% for 3 Murchison splits, 58\% for 1 Murray split and $19-29 \%$ for 3 Cold Bokkeveld splits). The potential for remaining contaminants was monitored by analyses of masses 48 and 49 in the purified $\mathrm{CO}_{2}$ gas, because these ion beams are less intense than that for mass 47 and can be strongly elevated in gases containing volatile organic contaminants. Previous studies have shown that such contaminants can lead to correlations between relatively small mass 47 excesses and proportionately greater excesses in masses 48 and 49 (Eiler and Schauble, 2004). While we never succeeded in completely removing masses 48 and 49 contaminants from these samples, no such correlations between $\Delta_{47}$ values and either mass 48 or 49 excesses were 
observed in these purified samples, suggesting that, in this case, the remaining contaminants are not associated with a mass-47 isobar. Consequently, no correction on measured $\Delta_{47}$ was made to account for masses 48 and 49 enrichments.

Although the sample purification procedures used in this study resemble those used in previous studies involving $\Delta_{47}$ measurements (e.g., Eiler and Schauble, 2004; Affek and Eiler, 2006; Ghosh et al., 2006), we apply them to considerably smaller samples. Therefore, we examined the effect of sample size on analytical fractionations associated with cryogenic purification, sulfide removal on silver phosphate, gas chromatography and mass spectrometric measurements. We observe a systematic effect of sample size on measured $\Delta_{47}$ value only for the gas chromatography step. In particular, $\Delta_{47}$ values of small samples (less than ca. $15 \mu$ moles) are systematically higher (by up to $0.2 \%$ ) in $\Delta_{47}$ value as compared to large (i.e., larger than $15 \mu$ mole) samples of that same gas subjected to the same gas chromatographic purification procedure. The magnitude of this $\Delta_{47}$ increase in small samples is independent of the isotopic compositions of the $\mathrm{CO}_{2}$ gas and varies only with the size of the gas (i.e., the smaller the size of $\mathrm{CO}_{2}$ gas, the bigger is its $\Delta_{47}$ increase after GC purification). It is possible that this sample-size effect reflects interaction between $\mathrm{CO}_{2}$ and adsorbed water in the $\mathrm{GC}$ column (although the column is routinely heated to $150^{\circ} \mathrm{C}$ between samples and the observed $\Delta_{47}$ increases are independent of the starting $\Delta_{47}$ value-inconsistent with the effects of $\mathrm{CO}_{2}-\mathrm{H}_{2} \mathrm{O}$ exchange). It is unlikely that the effect reflects fractionation associated with partial loss of the sample because we routinely achieved $>95 \%$ sample recovery of $\mathrm{CO}_{2}$. Nevertheless, despite the fact that the cause of this effect is unclear, it is a consistently and clearly observed artifact of GC purification. Therefore, we routinely standardized 
analyses of samples smaller than $15 \mu$ moles by comparison with standard $\mathrm{CO}_{2}$ gases of the same size that had been heated them to $1000^{\circ} \mathrm{C}$ to achieve the stochastic distribution. We tested the validity of this standardization method by measuring $\sim 5 \mu$ mole samples of $\mathrm{CO}_{2}$ prepared by acid digestion of small aliquots of carbonate standards having known $\Delta_{47}$ values (NBS-19 and Sigma carbonate; Ghosh et al., 2006). Values of $\Delta_{47}$ determined for these small aliquots of NBS-19 $(n=4)$ and Sigma carbonate $(n=4)$, standardized to heated gas of the same size, average $0.36 \pm 0.03(1 \sigma$, one standard error) and $0.56 \pm 0.06$ $(1 \sigma)$, respectively, consistent with their established values $(0.35 \pm 0.02,0.55 \pm 0.03$; Ghosh et al., 2006). Therefore, we believe that small samples can be analyzed with no systematic error provided they are compared to reference gases of the same size processed in the same way. Note, however, that while developing these methods of small sample analyses, some initial tests of NBS19 yielded $\mathrm{CO}_{2}$ having $\Delta_{47}$ values consistent with room-temperature equilibrium of $\mathrm{CO}_{2}$ gas $(\sim 0.98 \%)$. We believe this reflects the great susceptibility of small samples to exchange with water adsorbed on surfaces in the gas-handling apparatus, necessitating unusually aggressive measures to dry the apparatus between samples (i.e., relatively long baking).

It is possible that exposure of $\mathrm{CO}_{2}$ gas to dry $\mathrm{Ag}_{3} \mathrm{PO}_{4}$ may also influence the $\Delta_{47}$ of $\mathrm{CO}_{2}$ samples. To evaluate this possibility, we prepared clean $\mathrm{CO}_{2}$ gas and divided it into 2 splits of approximately equal size. We passed one split only through the GC column and the other split was first exposed to dry $\mathrm{Ag}_{3} \mathrm{PO}_{4}$ and then passed through the GC column. Values of $\Delta_{47}$ for these two splits were within 2 standard errors of each other, suggesting that exposure to dry $\mathrm{Ag}_{3} \mathrm{PO}_{4}$ does not influence the $\Delta_{47}$ value. Purifications on 
meteorite samples were performed only after such tests showed that a given batch of $\mathrm{Ag}_{3} \mathrm{PO}_{4}$ had negligible influences on $\Delta_{47}$ values.

\subsubsection{Mass spectrometric analysis}

Mass spectrometric analyses of purified $\mathrm{CO}_{2}$ were performed in dual inlet mode on a Finnigan-MAT 253 gas source isotope ratio mass spectrometer, configured to simultaneously measure masses $44,45,46,47,48$, and 49 . Detailed descriptions of the mass spectrometer configuration are given by Eiler and Schauble (2004) and Ghosh et al. (2006). Two types of dual inlet measurements were employed in the present study: 1) the 3 analyses made in 2005 were performed at signal intensities of $2 \mathrm{~V}$ for mass 44 in regular dual inlet mode; 2) the 4 analyses made in 2006 were performed at signal intensities of 3.4-7.4V for mass 44 in microvolume dual inlet mode (i.e., purified sample $\mathrm{CO}_{2}$ was cryogenically concentrated in a small volume during measurements, instead of being expanded to the sample bellow). Measurements of each sample gas consist of 6-10 analyses, each of which involves 10 cycles of sample-standard comparison with an ion integration time of 8 seconds per cycle. Pressure balance was maintained at mass 44 between sample gas and reference gas for all analyses. Values of $\Delta_{47}$ for each sample were established by comparison with same type of analyses of $\mathrm{CO}_{2}$ gases of similar size and bulk composition that had been heated to $1000^{\circ} \mathrm{C}$ (establishing the $\Delta_{47}=0 \%$ o reference scale for that sample size and purification procedure; Ghosh et al., 2006).

It has been previously shown that $\mathrm{CO}_{2}$ derived from acid digestion of $\mathrm{CM}$ chondrite carbonates differs in oxygen isotope composition from the terrestrial mass fractionation line (Clayton and Mayeda, 1984; Benedix et al., 2003). We must consider this fact when 
performing ion correction calculations associated with our measurements. To compute the $\delta^{13} \mathrm{C}$ and $\delta^{18} \mathrm{O}$ values for these samples from their measured masses 4445 and 46 abundances, we assumed the average carbonate $\Delta^{17} \mathrm{O}$ (recalculated from Benedix et al., 2003) for samples from the same $C M$ chondrite and a value of $\lambda=0.5164$ for the terrestrial mass fractionation line (Santrock et al., 1985). Values of $\delta^{13} \mathrm{C}$ and $\delta^{18} \mathrm{O}$ were standardized by comparison with $\mathrm{CO}_{2}$ generated by phosphoric acid digestion of NBS-19 and are reported vs. VPDB and VSMOW, respectively.

Carbonate formation temperatures were estimated from the $\Delta_{47}-\mathrm{T}$ calibration line for calcite and aragonite determined in Ghosh et al. (2006): $\Delta_{47}=\frac{0.0592 \times 10^{6}}{\mathrm{~T}^{2}}-0.02$, where $\mathrm{T}$ is in Kelvin. Note that $\Delta^{17} \mathrm{O}$ values also affect calculated $\Delta_{47}$ values since the $\Delta_{47}$ value depends on $\delta^{13} \mathrm{C}, \delta^{17} \mathrm{O}$ and $\delta^{18} \mathrm{O}$ values, and thus one must know or assume a $\Delta^{17} \mathrm{O}$ value when calculating $\Delta_{47}$ (Affek and Eiler, 2006). For example, a $1 \%$ o decrease in $\Delta^{17} \mathrm{O}$, if unrecognized or unaccounted for, would lead to a systematic error of $0.034 \%$ in $\Delta_{47}$. The $\Delta^{17} \mathrm{O}$ values of carbonates in any given CM chondrite vary by $0.1-0.8 \%$ (Murchison, $\mathrm{n}=5$; Murray, n=2; Clayton and Mayeda, 1984; Benedix et al., 2003), thus introducing $\sim 1$ to $\sim 5^{\circ} \mathrm{C}$ uncertainty in our temperature estimation.

Because our measurements were made on relatively small samples and required extensive purifications of $\mathrm{CO}_{2}$ produced by phosphoric acid digestion, they are less precise than previously reported temperatures based on carbonate clumped isotope thermometry (ca. $\pm 10^{\circ} \mathrm{C} 1 \sigma$ vs. \pm 2 to $3^{\circ} \mathrm{C} 1 \sigma$ ). External precisions of individual measurements of $\delta^{13} \mathrm{C}, \delta^{18} \mathrm{O}$ and $\Delta_{47}$ were estimated based on analyses of $\sim 5 \mu$ mole samples of $\mathrm{CO}_{2}$ prepared from small aliquots of carbonate standards and purified as for 
gases derived from samples. External precisions for these standard analyses averaged $0.14 \%$ for $\delta^{13} \mathrm{C}, 0.21 \%$ for $\delta^{18} \mathrm{O}$ and $0.041 \%$ for $\Delta_{47}$ (all $1 \sigma$; see section 2.3 .2 ). Similarly, analyses of clean $\sim 5 \mu$ mole $\mathrm{CO}_{2}$ gases exposed to dry $\mathrm{Ag}_{3} \mathrm{PO}_{4}$ and/or GC purification demonstrated external precisions averaging $0.05 \%$, $0.12 \%$ and $0.039 \%$, respectively (all $1 \sigma)$. We assume the larger of these two sets of external errors (those for small aliquots of carbonate standards) apply to our measurements of CM chondrite carbonates.

\section{RESULTS AND DISCUSSION}

\subsection{Temperatures of aqueous alteration and isotopic compositions of the alteration}

\section{fluid}

Six out of the seven temperatures of carbonate formation determined using the carbonate clumped isotope thermometer are within the range 20 to $35^{\circ} \mathrm{C}-$ indistinguishable from each other given our analytical precision (Table 1-1). The exception is a split from Cold Bokkeveld, which yielded a significantly higher temperature of $71^{\circ} \mathrm{C}$. The similarity in temperatures of aqueous alteration among most splits of Cold Bokkeveld, Murray, and Murchison suggests that they reacted with water at similar depths in and stages of evolution of their respective parent bodies. This result is broadly consistent with previous thermal models for the parent bodies of the carbonaceous chondrites, which suggest that aqueous alteration occurred within a relatively narrow range of locations within their host parent bodies (Young, 2001; McSween et al., 2002). Note, however, that the higher temperature we observe for one split of Cold Bokkeveld indicates that aqueous alteration occurred over a range of temperatures in at least one sample. 
If we interpret our results in the context of the model of Young (2001) that describes the thermal evolution of small planetesimals, water-rock reaction could have occurred within a $\sim 250 \mathrm{~m}$ thick zone, $1.8 \mathrm{~km}$ from the surface of an assumed $9 \mathrm{~km}$ radius parent body, although the higher temperature observed in one split requires that alteration occurred in a region, perhaps somewhat deeper, that was heated to well above the melting point of water ice. This compares with the estimate of an alteration zone 100-m-thick, $1 \mathrm{~km}$ from the surface previously inferred based on oxygen isotope geochemistry and the mineralogical alteration index (Benedix et al., 2003).

Our measurements of the $\delta^{13} \mathrm{C}$ and $\delta^{18} \mathrm{O}$ values of $\mathrm{CM}$ chondrite carbonates (in particular the calcite fraction extracted by our acid digestion methods) vary from $37.77 \%$ to $68.88 \%$ and from $28.21 \%$ to $34.61 \%$, respectively (Table 1 ). This variation is similar to that previously observed for calcites in $\mathrm{CM}$ chondrites $\left(\delta^{13} \mathrm{C}=23.7 \%\right.$ o to $67.8 \%$; $\delta^{18} \mathrm{O}=20.0 \%$ to $37.2 \%$; Clayton and Mayeda, 1984; Grady et al., 1988; Brearley et al., 1999; Benedix et al., 2003). Note, however, that the $\delta^{13} \mathrm{C}$ values of our samples of Murchison carbonates differ markedly from those in Grady et al. (1988) (60.09-68.88\%o vs. $31.6 \%$ to $45.1 \%$, respectively). An inverse correlation exists between $\delta^{13} \mathrm{C}$ and $\delta^{18} \mathrm{O}$ of carbonates considered in this study, in contrast to the weak positive correlation observed for eleven splits of Murchison in Grady et al. (1988). We suspect this difference reflects the fact that $\mathrm{CM}$ chondrites are highly heterogeneous breccias and contain alteration phases that may have formed over a range of conditions; thus, it is unsurprising that repeated sampling of small aliquots of such materials can produce divergent results.

Given the temperatures of carbonate growth summarized above and previous experimental calibration of the oxygen isotope fractionation between calcite and water 
(Kim and O'Neil, 1997), we can estimate the oxygen isotope compositions of waters from which the carbonates we analyzed grew. These waters varied in $\delta^{18} \mathrm{O}_{\text {SMOw }}$ between values of $1.8 \%$ and $7.8 \%$ o $( \pm 2 \%, 1 \sigma)$. If we assume that the carbonates we analyzed have $\Delta^{17} \mathrm{O}$ values equal to the averages previously determined by Bendix et al. (2003), our results also indicate that the $\delta^{17} \mathrm{O}$ values of waters from which carbonates grew varied between $-0.2 \%$ and $2.9 \%$. These $\delta^{18} \mathrm{O}$ and $\delta^{17} \mathrm{O}$ values of carbonate formation water are significantly lower than those estimated for the primary source of water that altered the $\mathrm{CM}$ chondrites $\left(\delta^{18} \mathrm{O}\right.$ ca. $\geq 15.9 \%$, $\delta^{17} \mathrm{O}$ ca. $\geq 9.2 \%$; Clayton and Mayeda, 1999). This difference in isotopic composition between model reactant water and the water from which carbonates grew suggests that water evolves toward lower $\delta^{18} \mathrm{O}, \delta^{17} \mathrm{O}$ and $\Delta^{17} \mathrm{O}$ as a result of reaction with host rock (Clayton and Mayeda, 1984; Clayton and Mayeda, 1999) (Figure 1-1).

We interpret our results in the context of a quantitative model for the aqueous alteration of $\mathrm{CM}$ chondrites. This model simplifies many aspects of this process, but provides a framework for testing the internal consistency of our interpretations. First, we assume, following Clayton and Mayeda (1999) and Eiler and Kitchen (2004), that the most volumetrically important alteration reactions (i.e., silicate hydration) can be represented by:

$$
\mathrm{Mg}_{2} \mathrm{SiO}_{4}+\mathrm{MgSiO}_{3}+2 \mathrm{H}_{2} \mathrm{O} \rightarrow \mathrm{Mg}_{3} \mathrm{Si}_{2} \mathrm{O}_{5}(\mathrm{OH})_{4}
$$

We define the reaction progress parameter (Clayton and Mayeda, 1999), $p$, as $p=\frac{f}{x}$, where $f$ is the fraction of initial olivine and pyroxene that has been converted to serpentine (on a molar oxygen basis) and $x$ is the ratio of moles of $\mathrm{O}$ in reactant water to 
moles of $\mathrm{O}$ in reactant olivine and pyroxene (thus $p$ denotes the ratio of moles of oxygen in the reacted rock to moles of oxygen in initial water). We assume that the initial oxygen isotopic composition of reactant water (i.e., prior to any reaction with anhydrous silicate) was $\delta^{18} \mathrm{O}_{\mathrm{w}, \mathrm{i}}=28.1 \%, \delta^{17} \mathrm{O}_{\mathrm{w}, \mathrm{i}}=17.7 \%$, and that the oxygen isotope composition of reactant silicate was $\delta^{18} \mathrm{O}_{\mathrm{r}, \mathrm{i}}=-4.2 \%, \delta^{17} \mathrm{O}_{\mathrm{r}, \mathrm{i}}=-7.4 \%$ (Clayton and Mayeda, 1999).

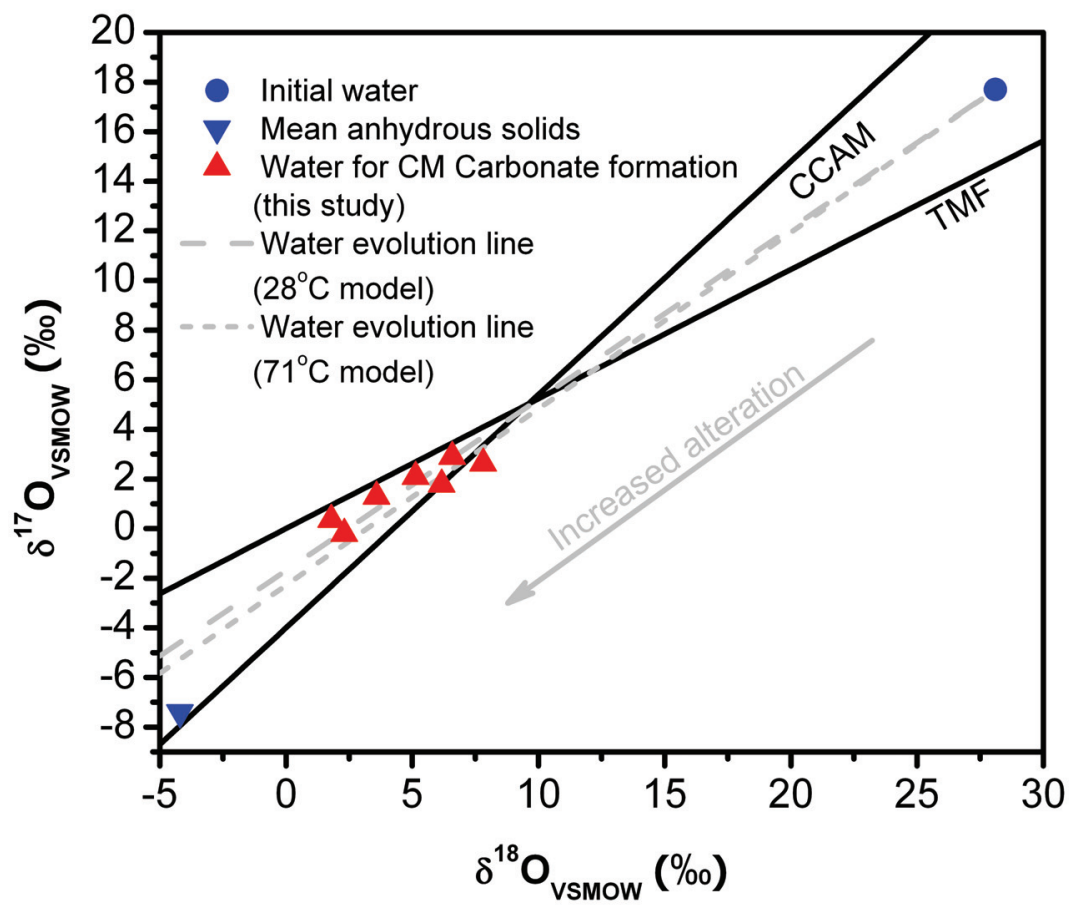

Figure 1-1 Oxygen isotope compositions (all values reported vs. VSMOW) of water in equilibrium with $\mathrm{CM}$ chondrite carbonates at their known growth temperatures (triangles) and water calculated by the forward model of aqueous alteration described in the text (circle and dashed lines; note models for two different assumed temperatures of water-rock reaction are shown). The terrestrial mass fractionation line ('TMF') and carbonaceous chondrite anhydrous mineral line ('CCAM') are shown for reference. The inverted triangle shows the location of typical anhydrous solids in CM chondrites. Data are from this study (Table 1-1) and Clayton and Mayeda (1999) (see figure legend for details). 
Most of our model calculations adopt a serpentine-water oxygen isotope fractionation of $\Delta^{18} \mathrm{O}_{\mathrm{s}-\mathrm{w}}=12.5 \%$ (Wenner and Taylor, 1971), appropriate for equilibration at $28^{\circ} \mathrm{C}$. This corresponds to a ${ }^{17} \mathrm{O} /{ }^{16} \mathrm{O}$ fractionation between serpentine and water of $\Delta^{17} \mathrm{O}_{\mathrm{s}-\mathrm{w}}=6.4 \%$ (assuming a normal mass-dependent fractionation between serpentine and water). We selected a model temperature of $28^{\circ} \mathrm{C}$ because it is a reasonable approximation of the temperatures of carbonate growth for most of our samples (though silicate hydration need not occur at the same temperatures as carbonate precipitation) and it is similar to temperatures of aqueous alteration assumed by previous models of this kind (e.g., Clayton and Mayeda, 1999). While we are aware of no definitive reports of serpentinization occurring at $28^{\circ} \mathrm{C}$ in terrestrial rocks, both lab experiments and field observations have been used to suggest that serpentinization (and, important for our further discussion of this model in section 3.2 of this paper, concurrent $\mathrm{H}_{2}$ generation) occurs at earth-surface temperatures (Neal and Stanger, 1983; Stevens and McKinley, 1995; Stevens and McKinley, 2000). The lowest measured temperature of a serpentinization reaction is $45^{\circ} \mathrm{C}$, in the Lost City hydrothermal field, determined using a hydrogen isotope geothermometer (Proskurowski et al., 2006). However, the authors of that study suggested that this low temperature reflects re-equilibration of hydrogen isotopes after serpentinization at $110-150^{\circ} \mathrm{C}$. Experimental studies suggest that hydration reactions are generally geologically fast (e.g., at $245^{\circ} \mathrm{C}$ with a rock/water ratio of $2.5 / 1$, $\sim 28 \%$ enstatite converts to serpentine within 6 days; Martin and Fyfe, 1970) and, in most circumstances, the rate limiting step is transport of water to the reaction site rather than the temperature-dependent kinetics of the reaction itself (Martin and Fyfe, 1970). We conclude that it is plausible to imagine silicate hydration on the CM parent bodies 
occurring at temperatures as low as $28^{\circ} \mathrm{C}$, although a more definitive understanding of this problem will require further experimental studies of the kinetics of silicate hydration at such low temperatures. We also present a version of this model that assumes serpentine-water oxygen isotope fractionations more appropriate for a higher temperature of $71^{\circ} \mathrm{C}$ - the highest carbonate precipitation temperature observed in this study $\left(\Delta^{18} \mathrm{O}_{\mathrm{s}-}\right.$ ${ }_{\mathrm{w}}=8.5 \%$, and $\Delta^{17} \mathrm{O}_{\mathrm{s}-\mathrm{w}}=4.4 \%$; Wenner and Taylor, 1971$)($ Figure $1-1)$.

Given the parameters summarized above, the oxygen isotope composition of aqueous fluid after reaction is given by Clayton and Mayeda (1999):

$$
\begin{aligned}
\delta^{18} \mathrm{O}_{\mathrm{w}, \mathrm{f}} & =\frac{\delta^{18} \mathrm{O}_{\mathrm{w}, \mathrm{i}}+\left(\delta^{18} \mathrm{O}_{\mathrm{r}, \mathrm{i}}-\frac{9}{7} \Delta^{18} \mathrm{O}_{\mathrm{s}-\mathrm{w}}\right) \mathrm{p}}{1+\mathrm{p}} \\
\delta^{17} \mathrm{O}_{\mathrm{w}, \mathrm{f}} & =\frac{\delta^{17} \mathrm{O}_{\mathrm{w}, \mathrm{i}}+\left(\delta^{17} \mathrm{O}_{\mathrm{r}, \mathrm{i}}-\frac{9}{7} \Delta^{17} \mathrm{O}_{\mathrm{s}-\mathrm{w}}\right) \mathrm{p}}{1+\mathrm{p}} \\
\Delta^{17} \mathrm{O}_{\mathrm{w}, \mathrm{f}} & =\left(\frac{1+\delta^{17} \mathrm{O}_{\mathrm{w}, \mathrm{f}} / 1000}{\left(1+\delta^{18} \mathrm{O}_{\mathrm{w}, \mathrm{f}} / 1000\right)^{0.5164}}-1\right) \times 1000
\end{aligned}
$$

Note that $\Delta^{17} \mathrm{O}_{\mathrm{w}, \mathrm{f}}$ values are independent of alteration temperature and vary only as a function of $\mathrm{p}$ once the initial isotopic compositions of water and rock (i.e., $\Delta^{17} \mathrm{O}_{\mathrm{w}, \mathrm{i}}$ and $\Delta \Delta^{17} \mathrm{O}_{\mathrm{r}, \mathrm{i}}$ ) are specified. Therefore $\Delta \Delta^{17} \mathrm{O}_{\mathrm{w}, \mathrm{f}}$ ( i.e., $\Delta^{17} \mathrm{O}_{\text {carbonate, }}$ assuming carbonate formed in isotopic equilibrium with its formation water) can be used as an indicator for the extent of alteration. In contrast, the slope of the correlation between $\delta^{18} \mathrm{O}_{\mathrm{w}, \mathrm{f}}$ and $\delta^{17} \mathrm{O}_{\mathrm{w}, \mathrm{f}}$ is influenced by the alteration temperature (the higher the alteration temperature, the steeper is the line of $\delta^{18} \mathrm{O}_{\mathrm{w}, \mathrm{f}}$ vs. $\left.\delta^{17} \mathrm{O}_{\mathrm{w}, \mathrm{f}}\right)$.

Our results imply that the water that precipitated carbonate in Cold Bokkeveld varied significantly in oxygen isotope composition over the course of that rock's 
alteration history (Table 1-1). In the context of the model trend depicting the expected isotopic evolution of reactant water illustrated in Figure 1-1 (i.e., the higher extent of alteration the lower $\delta^{18} \mathrm{O}$ of the water), this water had experienced less previous reaction when the precipitation temperature was high and more previous reaction when the precipitation temperature was low; i.e., the rock was cooling as alteration proceeded. Previous studies of the minor and trace element (Riciputi et al., 1994) and stable isotope geochemistry (Grady et al., 1988) of carbonates in CM chondrites have also suggested that their parental waters varied in composition both spatially and temporally.

\subsection{Correlation between $\delta^{13} \mathrm{C}$ of the carbonates and $\delta^{18} \mathrm{O}$ of their formation waters: evidence for methane generation}

The $\delta^{13} \mathrm{C}$ values of carbonates in the $\mathrm{CM}$ chondrites exhibit a negative correlation with the oxygen isotope compositions of the waters from which they grew (Figure 1-2). If we interpret this correlation in the context of the model water evolution trend marked in Figure 1-1, it suggests that the pool of dissolved inorganic carbon from which carbonate grew evolved from lower $\delta^{13} \mathrm{C}$ to higher $\delta^{13} \mathrm{C}$ as alteration proceeded. This interpretation is supported by weak correlations previously observed between the alteration index and both oxygen and carbon isotope compositions of CM chondrite carbonates (Grady et al., 1988), which was interpreted by the authors as possible indications that isotopically distinct components were altered and added to the fluid phase over the course of aqueous alteration. 


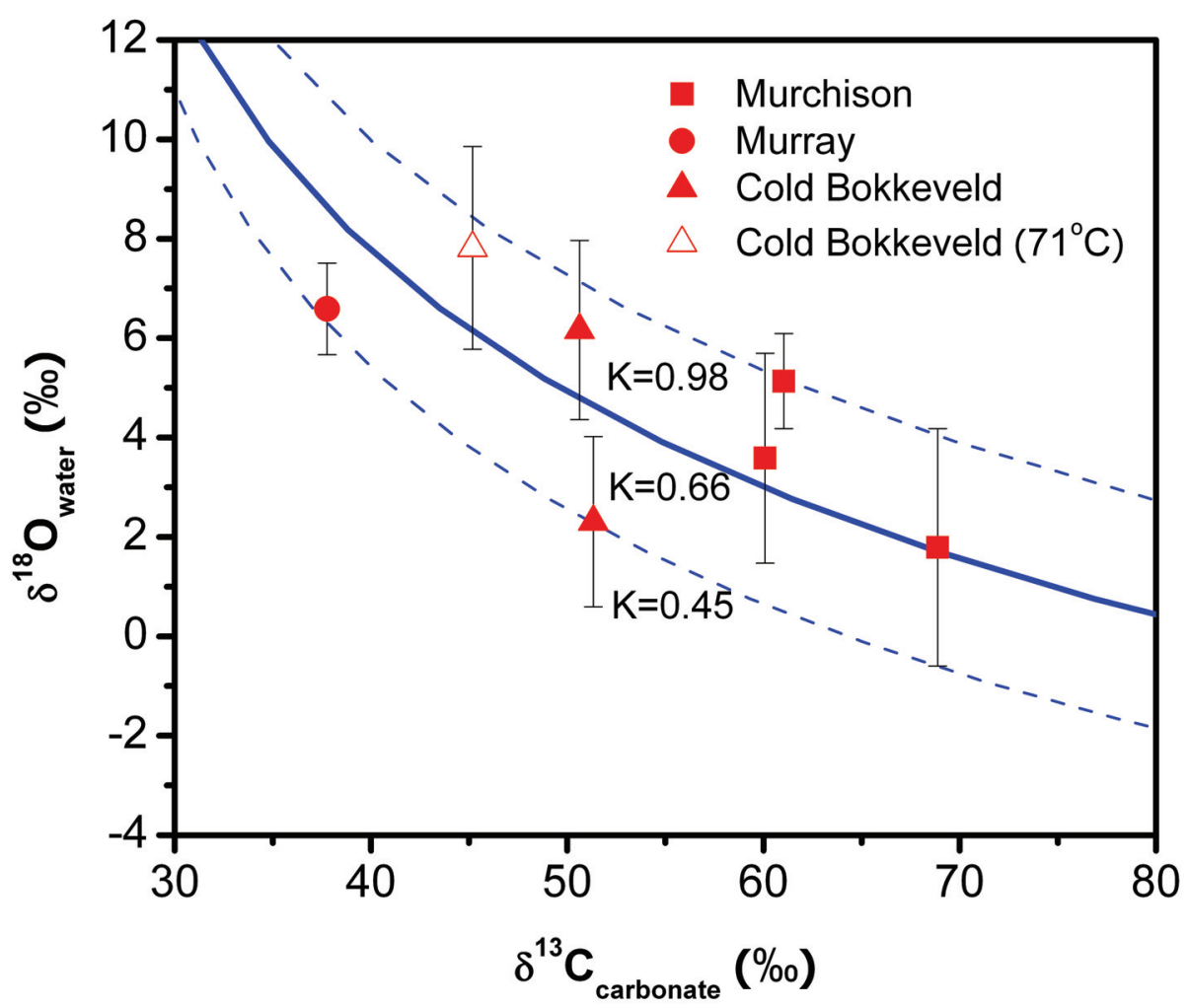

Figure 1-2. Comparison of $\delta^{13} \mathrm{C}_{\mathrm{VPDB}}$ values of carbonates in the $\mathrm{CM}$ chondrites to the $\delta^{18} \mathrm{O}_{\mathrm{VSMOW}}$ values of the waters from which they grew (based on the known $\delta^{18} \mathrm{O}$ values and growth temperatures of those carbonates and the temperature-dependent carbonate-water fractionation given by Kim and O'Neil, 1997). Curves indicate trends predicted by our model of coupled serpentinization and reduction of dissolved inorganic carbon to form methane. Values of ' $\mathrm{K}$ ' for each model trend indicate the relative rates of methane production to silicate hydration (see text for details). Error bars indicate internal standard errors of each analysis; external errors, including contributions from all sources, average ca. $2 \%$ in $\delta^{18} \mathrm{O}$ and ca. $0.2 \%$ in $\delta^{13} \mathrm{C}$. See Table $1-1$ for further details.

It is possible that the trend in Figure 1-2 reflects oxidation and dissolution of ${ }^{13} \mathrm{C}$ enriched carbon in the reactant assemblage. Carbon reservoirs, other than carbonates, in $\mathrm{CM}$ chondrites include organics $\left(\delta^{13} \mathrm{C}_{\mathrm{PDB}}\right.$ of ca. -36 to $41 \%$ for the major constituents; Sephton and Gilmour, 2001) and presolar grains $\left(\delta^{13} \mathrm{C}_{\mathrm{PDB}}\right.$ of bulk measurements on some presolar phases vary up to ca. 1500\%; Yang and Epstein, 1984). Organic constituents are 
lower in $\delta^{13} \mathrm{C}$ than the highest values observed in $\mathrm{CM}$ chondrite carbonates and so they cannot be the sole contributors to observed carbon isotope variations of those carbonates. Most presolar phases are highly resistant to chemical oxidation and dissolution (Yang and Epstein, 1984) and so should have been inert under the relatively mild conditions at which $\mathrm{CM}$ chondrites underwent aqueous alteration. Presolar diamond and graphite might be more vulnerable to aqueous alteration, but their average $\delta^{13} \mathrm{C}$ is also lower than that of CM chondrite carbonates (Hoppe et al., 1995). Thus, this hypothesis seems implausible.

Alternatively, ${ }^{13} \mathrm{C}$ enrichment could have accompanied aqueous alteration if it occurred in an open system (Wilson et al., 1999) from which $\mathrm{CO}_{2}$ vapor was lost by a mechanism that involved a kinetic isotope fractionation. Such processes lead to ${ }^{13} \mathrm{C}$ enrichment of dissolved inorganic carbon in evaporating Dead Sea brines (Stiller et al., 1985), caliches (Knauth et al., 2003) and cryogenic weathering products (Clark and Lauriol, 1992). However, significant $\mathrm{CO}_{2}$ degassing in evaporating Dead Sea brines is caused by low $\mathrm{pH}$ of those brines (3.7-6.0; Stiller et al., 1985). Alteration fluids that reacted with the $\mathrm{CM}$ chondrites are inferred to have had far higher $\mathrm{pH}$ values (10-12; Zolensky, 1984) and are not expected to have evolved a substantial fraction of their dissolved inorganic carbon as $\mathrm{CO}_{2}$. More importantly, kinetic isotope effects associated with evaporation of carbonate-bearing aqueous solutions typically also lead to increases in the $\delta^{18} \mathrm{O}$ value of the residual solution (Stiller et al., 1985; Knauth et al., 2003). There is no evidence for such ${ }^{18} \mathrm{O}$ enrichment in the solutions that altered the $\mathrm{CM}$ chondritesin fact, the opposite trend is observed in Figure 1-2. Therefore, this process also seems like a poor explanation of our observations. 
Finally, aqueous alteration of the CM parent body could have led to an increase in $\delta^{13} \mathrm{C}$ of dissolved inorganic carbon in the pore waters of that body if alteration was accompanied by production and escape of low $-\delta^{13} \mathrm{C} \mathrm{CH}_{4}$. A terrestrial analogue for this process is serpentinization of ultramafic rocks, during which dissolved inorganic carbon species are converted to $\mathrm{CH}_{4}$ by the reaction (Horita and Berndt, 1999) :

$$
\mathrm{HCO}_{3}^{-}+4 \mathrm{H}_{2} \rightarrow \mathrm{CH}_{4}+\mathrm{OH}^{-}+2 \mathrm{H}_{2} \mathrm{O}
$$

Palmer and Drummond (1986) and Shock (1988) suggest that reactions like reaction (II) require a condensed phase catalyst to be geologically significant. Chromite, Fe-Ni alloys, and magnetite have been shown to catalyze this reaction (Horita and Berndt, 1999; Foustoukos and Seyfried, 2004) and these and similar phases are abundant constituents of the $\mathrm{CM}$ chondrites (Brearley and Jones, 1998). At $200^{\circ} \mathrm{C}$ (a temperature at which this reaction occurs over laboratory time scales), the $\mathrm{CH}_{4}$ produced by this reaction is ca. $60 \%$ lower in $\delta^{13} \mathrm{C}$ than the residual inorganic carbon (Horita and Berndt, 1999). Based on the temperature dependence of similar reactions (Horita, 2001), we suggest the fractionation at $28^{\circ} \mathrm{C}$ (assuming the reaction could proceed over geological timescales at such low temperatures) could be as large as $90 \%$. In this case, the observed range in $\delta^{13} \mathrm{C}$ values for CM chondrite carbonates could be produced by ca. $38 \%$ loss of the dissolved inorganic carbon pool through reduction to and loss of $\mathrm{CH}_{4}$. If we instead assume the experimentally measured high-temperature fractionation of $60 \%$, then $51 \%$ loss would be required.

The carbon isotope composition of dissolved inorganic carbon varies with the progress of reaction (II), by the relation:

$$
\delta^{13} C_{\mathrm{HCO}_{3}^{-}, \mathrm{f}}=1000 \ln \alpha_{\mathrm{HCO}_{3}^{-}, \mathrm{f}}=1000 \ln \left(\alpha_{\mathrm{HCO}_{3}^{-}, \mathrm{i}} F^{\alpha{ }^{13} C_{\mathrm{CH}_{4}-\mathrm{HCO}_{3}}^{-1}}\right)
$$


where $F$ is the fraction of reactant $\mathrm{HCO}_{3}^{-}$that remains and $\alpha^{13} \mathrm{C}_{\mathrm{CH}_{4}-\mathrm{HCO}_{3}}$ is the kinetic carbon isotope fractionation associated with reaction (II) (i.e., $90 \%$ ).

We prescribed that the progress of reaction (II) is a function of the progress of reaction (I), which is reasonable because $\mathrm{H}_{2}$ is a reactant in reaction I and is produced in Fe-bearing systems as a result of reactions like reaction I (e.g., through olivine oxidation; Oze and Sharma, 2005, or Fe metal oxidation; Zolotov and Shock, 2004). This leads to:

$$
\mathrm{F}=\frac{\left[\mathrm{HCO}_{3}^{-}\right]_{\mathrm{f}}}{\left[\mathrm{HCO}_{3}^{-}\right]_{\mathrm{i}}}=1-\frac{\int \mathrm{d}\left[\mathrm{HCO}_{3}^{-}\right]}{\left[\mathrm{HCO}_{3}^{-}\right]_{\mathrm{i}}}=1-\frac{\int-\mathrm{K}\left[\mathrm{HCO}_{3}^{-}\right] \mathrm{p} \mathrm{dp}}{\left[\mathrm{HCO}_{3}^{-}\right]_{\mathrm{i}}},
$$

where $\left[\mathrm{HCO}_{3}^{-}\right]$is the concentration of $\mathrm{HCO}_{3}^{-}$and $\mathrm{K}$ is the ratio of the progress of reactions (I) and (II). Equation 5 simplifies to: $F=\mathrm{e}^{-\frac{\mathrm{Kp} p^{2}}{2}}$. Thus, both the $\delta^{18} \mathrm{O}$ of water and the $\delta^{13} \mathrm{C}$ of inorganic carbon are functions of $\mathrm{p}$, and the position of a sample along the trend in Figure 1-2 depends only on $\mathrm{p}$ and $\mathrm{K}$. If we assume that the initial $\delta^{13} \mathrm{C}$ value of dissolved inorganic carbon was $22.8 \%$, the lowest $\delta^{13} \mathrm{C}$ value observed for carbonates in the CM chondrites (23.7\% ; Grady et al., 1988) minus the carbon isotope fractionation between dissolved inorganic carbon and calcite ( $\sim .9 \%$; Rubinson and Clayton 1969), then the trend in Figure 1-2 is best fit by a value for $\mathrm{K}=\frac{-2 \ln F}{p^{2}}$ of 0.66 , with $\mathrm{p}$ varying from 0.72 to 1.19 among samples. Because $p$ denotes the ratio of moles of oxygen in the reacted rock to moles of oxygen in initial water, this variation of $\mathrm{p}$ among samples indicates that water in some samples underwent $\sim 1.6$ times reaction with silicates than water in other samples. 


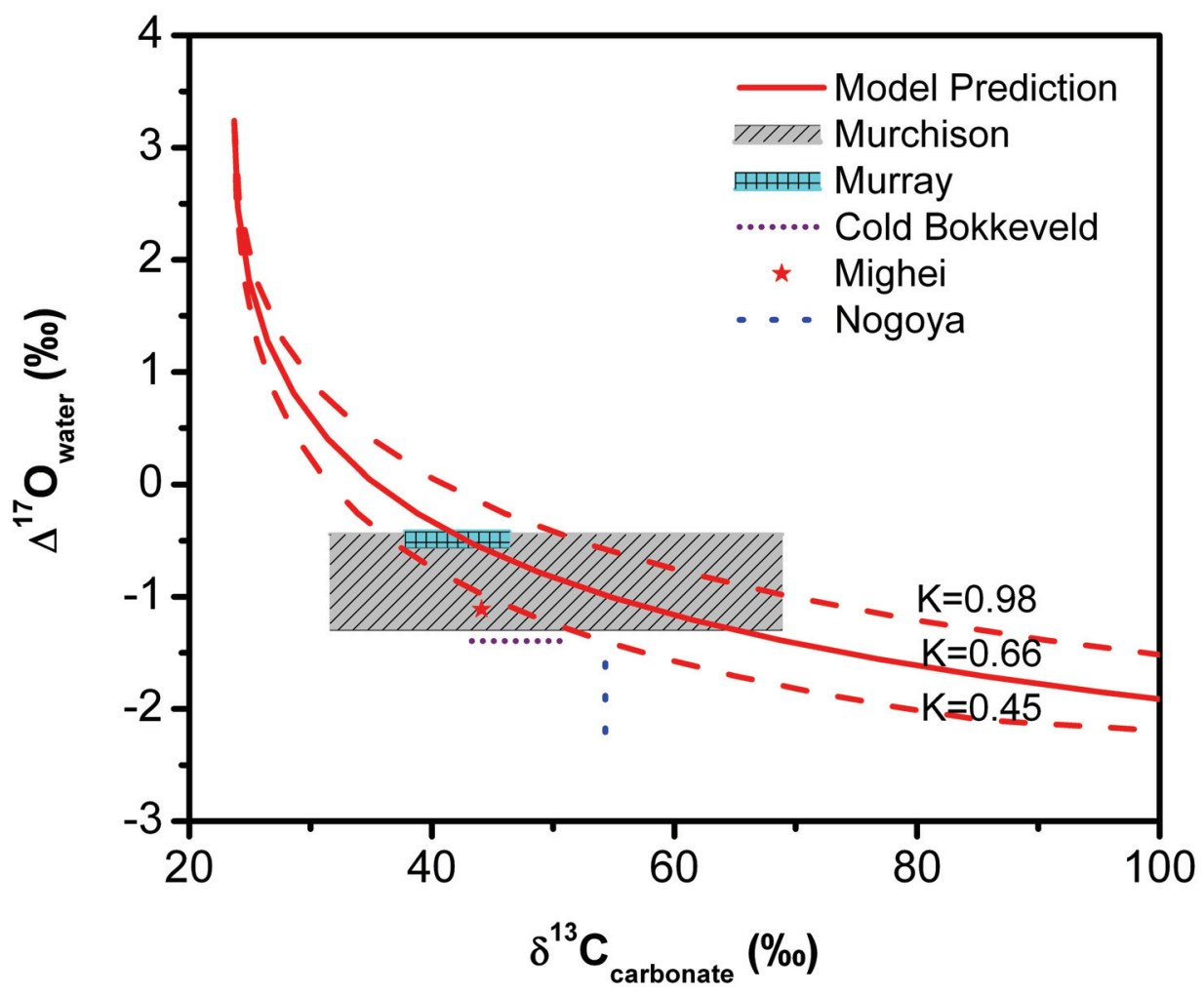

Figure 1-3. Predicted inverse correlation between $\Delta^{17} \mathrm{O}_{\mathrm{VSMOW}}$ of the formation water and $\delta^{13} \mathrm{C}_{\mathrm{VPDB}}$ of the carbonate during aqueous alteration of the $\mathrm{CM}$ chondrite parent body at $28^{\circ} \mathrm{C}$. Also shown for comparison are reported ranges of $\delta^{13} \mathrm{C}$ and $\Delta{ }^{17} \mathrm{O}$ values of carbonate (calcite portion) in $\mathrm{CM}$ chondrites (Clayton and Mayeda 1984; Grady et al. 1988; Benedix et al. 2004; this study). ' $\mathrm{K}$ ' is the same as in Figure 1-2. Note that reported $\delta^{13} \mathrm{C}$ and $\Delta^{17} \mathrm{O}$ values are not from the same aliquots of samples.

Our model also predicts an inverse correlation between $\delta^{17} \mathrm{O}$ and $\Delta^{17} \mathrm{O}$ of the formation water on one hand and $\delta^{13} \mathrm{C}$ of the carbonate on the other (Figure 1-3). Most of the available measurements of $\delta^{13} \mathrm{C}$ (Grady et al., 1988) and $\Delta^{17} \mathrm{O}$ (Clayton and Mayeda, 1984; Benedix et al., 2003) in carbonates from the CM chondrites were made on separate sample aliquots and thus do not clearly test this prediction (although the ranges of their variations are broadly consistent with our predicted trend; Figure 1-3). The only 
exception is a recent study on paired Antarctic CM chondrites (Tyra et al., 2007), which observed an inverse correlations between $\delta^{13} \mathrm{C}$ and $\Delta^{17} \mathrm{O}$, as predicted. However, this study also observed that both $\delta^{13} \mathrm{C}$ and $\Delta^{17} \mathrm{O}$ correlate with ${ }^{14} \mathrm{C}$ content in the carbonates, and thus the correlation between $\delta^{13} \mathrm{C}$ and $\Delta^{17} \mathrm{O}$ could be caused or modified by terrestrial weathering (i.e., mixing or replacement of primary carbonate with lower $\delta^{13} \mathrm{C}$, higher $\Delta{ }^{17} \mathrm{O}$ and ${ }^{14} \mathrm{C}$ terrestrial carbonates) (Tyra et al., 2007).

The correlation between $\Delta{ }^{17} \mathrm{O}_{\text {water }}$ and $\delta{ }^{13} \mathrm{C}_{\text {carbonate }}$ predicted by our model (Figure 13) implies that carbonates should vary in $\Delta^{17} \mathrm{O}$ between different splits of the same meteorite for both Murchison and Cold Bokkeveld (i.e., because they vary in $\delta^{13} \mathrm{C}$; Table 1-1). Therefore, if our model is correct, then our assumption that $\Delta^{17} \mathrm{O}$ values of carbonates from a given meteorite are uniform and equal to the previously measured average for carbonate from that meteorite introduced errors in $\Delta_{47}$ (which is calculated based on a known or assumed $\Delta^{17} \mathrm{O}$ value) and $\delta^{18} \mathrm{O}_{\text {water }}$ (which depends, in part, on $\Delta_{47}$ ). These errors might potentially influence the correlation in Figure 1-2, which is the primary justification of our methane generation model. A sensitivity analysis suggests that this factor is unlikely to lead to large changes: based on observed $\delta^{13} \mathrm{C}_{\text {carbonate }}$ values and our model trend in Figure 1-3, values of $\Delta^{17} \mathrm{O}$ in carbonates are expected to vary by $0.3 \%$ or less among different splits from the same meteorite; this would result in variations of only $0.01 \%$ in ion-corrected $\Delta_{47}$ values. These variations would be within our nominal analytical uncertainties. It is possible to calculate an alternate version of Figure 1-2 that assumes the model trend in Figure 1-3 is correct. However, this is an essentially circular exercise (i.e., because the model trend in Figure 1-3 depends, in part, on the fit to data in Figure 1-2) and cannot clarify the issue. We suggest that future 
studies should attempt to apply both $\Delta_{47}$ and $\Delta^{17} \mathrm{O}$ analyses to aliquots of $\mathrm{CO}_{2}$ produced by acid digestion of carbonates in each $\mathrm{CM}$ chondrite.

\subsection{Eh, pH of the alteration fluid estimated through the GEM-Selektor program}

Reaction (II) will proceed to the right only under specific Eh conditions. We estimated these conditions using the GEM-Selektor program (Kulik et al. 1997; Kulik et al. 2000), which determines the equilibrium species distribution in a system through Gibbs Energy minimization (Bethke, 1996). This method does not depend on the prealteration mineralogy (an uncertainty in previous models of this kind; Zolensky et al., 1989; Rosenberg et al., 2001).

Our model of the chemistry of fluids in equilibrium with the alteration assemblage in the $\mathrm{CM}$ chondrites considers $\mathrm{Si}, \mathrm{Fe}, \mathrm{Mg}, \mathrm{S}$ and $\mathrm{Ca}$ and neglects $\mathrm{Al}, \mathrm{Cr}, \mathrm{K}, \mathrm{Ni}$ and other minor elements. Calculations were performed for $28^{\circ} \mathrm{C}, 1 \mathrm{~atm}$, unless stated otherwise, with a bulk chemical composition as estimated by Browning and Bourcier (1998), assuming that aqueous alteration occurred without gain or loss of major cations (Table 12). During the simulation, we monitored the redox condition of the system by adding variable amounts of $\mathrm{H}_{2}(0-1$ grams) into the system (which typically consisted of $\sim 100$ grams of rock and 36 grams of water, and thus corresponds to $p=1.023$ ) and observed the concurrent changes of carbon speciation.

Controls were imposed on the final (post-alteration) mineral products to suppress the precipitation of mineral phases that generally do not form at these low temperatures (e.g., andradite, tremolite and troilite etc.) or are kinetically inhibited (e.g., quartz). Chrysotile is the only Mg-phyllosilicate allowed to form in the simulation, consistent with the fact 


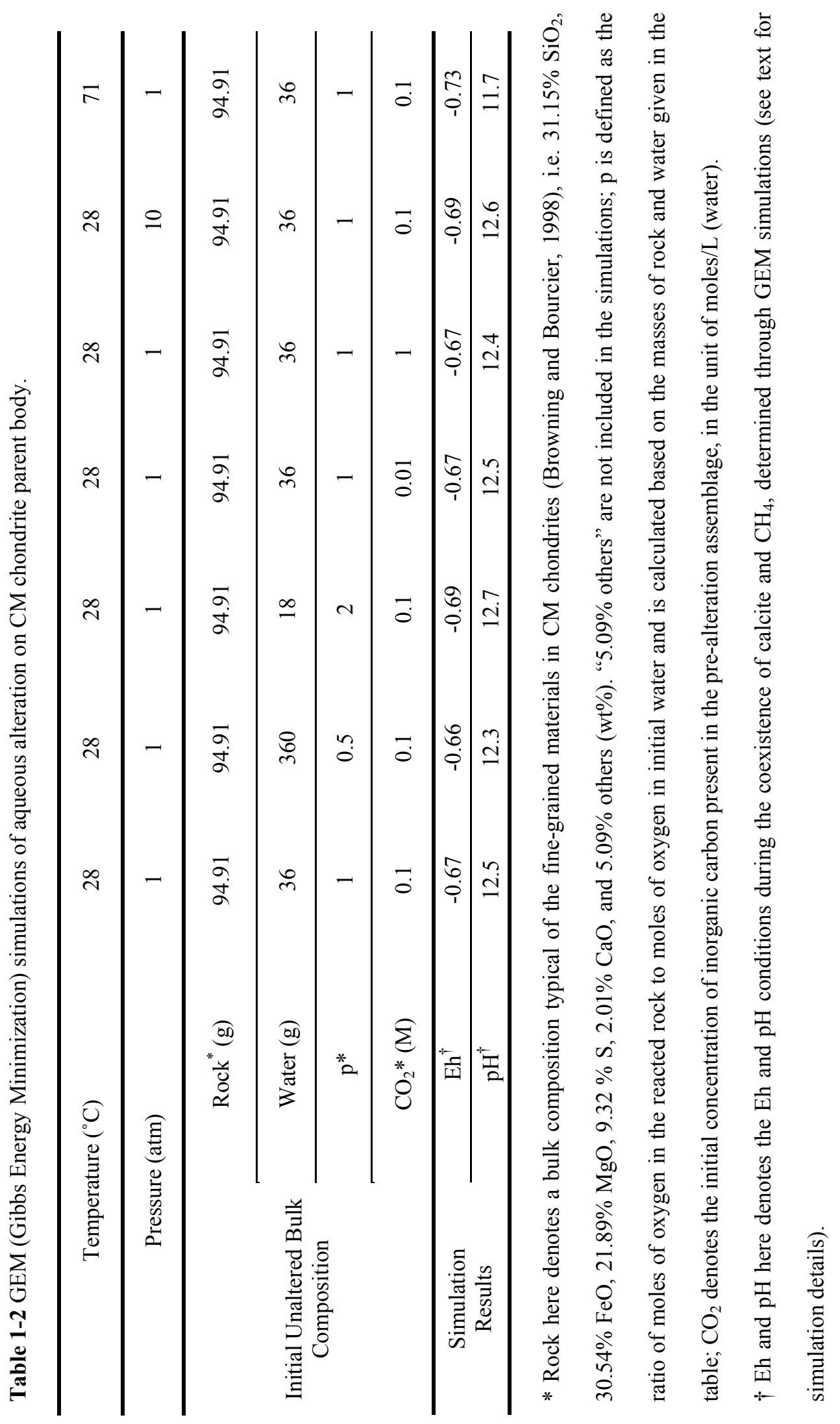


that it is the dominant Mg-rich alteration phase observed in carbonaceous chondrites (Brearley and Jones, 1998; Rosenberg et al., 2001). A typical product assemblage in our simulation included: chrysotile, greenalite, pyrite, pyrrhotite and $\mathrm{CH}_{4}$ (more reducing conditions); chrysotile, greenalite, pyrite, goethite, gypsum and calcite (less reducing conditions). All the thermodynamic data employed in the calculations are from the Nagra/PSI Chemical Thermodynamic Data Base 01/01 (Hummel et al., 2002) and an updated version of thermodynamic database (slop98.dat) for SUPCRT92 (Johnson et al., 1992), as implemented in the GEM-Selektor Program (Kulik et al., 2000).

Given these constraints, we found that the coexistence of carbonate and $\mathrm{CH}_{4}$ requires an Eh of -0.67 and $\mathrm{pH}$ of 12.5 . Both $\mathrm{Eh}$ and $\mathrm{pH}$ are inversely correlated with the assumed temperature (decreasing to -0.73 and 11.7 at $71^{\circ} \mathrm{C}$ ), but neither of them is strongly dependent on reasonable variations of other model parameters (e.g. water/rock ratios, alteration pressures, and initial $\mathrm{CO}_{2}$ concentrations etc., Table 2). For a given set of independent constraints, $\mathrm{pH}$ of the alteration fluid is inversely correlated with Eh. Note that this calculation (as for similar previous calculations; Zolensky et al., 1989; Rosenberg et al., 2001) assumes equilibrium with respect to redox reactions in the alteration assemblage, which might not apply (Bethke, 1996).

\section{IMPLICATIONS}

The temperatures of carbonate precipitation in representative $\mathrm{CM}$ chondrites, as constrained by carbonate clumped isotope thermometry, are within the range of (though more specific than) previous estimates based on mineral stability and oxygen isotope fractionation between different matrix phases. We observe a negative correlation between 
$\delta^{13} \mathrm{C}_{\mathrm{PDB}}$ of carbonates and $\delta^{18} \mathrm{O}_{\mathrm{SMOW}}$ of the water from which those carbonates grew. This correlation can be explained if carbonate growth was accompanied by the formation and escape of ${ }^{13} \mathrm{C}$-depleted methane during aqueous alteration on the $\mathrm{CM}$ chondrite parent bodies.

Our conclusion that aqueous alteration of the CM chondrites was accompanied by formation and loss of methane implies that methane generation in the interiors of planets and planetessimals may have been a widespread phenomenon in the evolutionary history of the solar system. Several recent studies (Formisano et al. 2004; Lyons et al. 2005; Oze and Sharma 2005) invoked serpentinization and hydrothermal alteration sources of atmospheric methane detected on Mars, and analogous processes could be considered to explain methane found on other solar system objects, such as Titan (Niemann et al., 2005), Triton (Cruikshank et al., 1993), Pluto (Owen et al., 1993) and Kuiper belt objects (Brown et al. 1997; Barucci et al. 2005; Brown et al. 2005; Licandro et al. 2006). It is unclear whether the details of the alteration model we propose (i.e., reactants, temperatures, Eh, $\mathrm{pH}$, stoichiometries) could have any direct relevance for Mars, which has undergone extensive magmatic differentiation and thus consists of relatively volatilepoor igneous rocks that differ in many respects from the carbonaceous chondrites. However, the model we suggest for methane generation in the $\mathrm{CM}$ chondrite parent bodies plausibly applies to at least some portions of the interiors of Titan and other outer solar system bodies, especially early during their histories. For example, it is possible that the sub-surface of Titan contains abundant liquid water-ammonia solution with temperatures up to $0^{\circ} \mathrm{C}$ (Grasset and Pargamin, 2005) and possibly higher early in Titan's history (Atreya et al., 2006; Tobie et al., 2006). This reduced, water-rich interior provides 
an environment where silicate alteration reactions such as those we consider in our model could take place. Currently, methane in the atmosphere of Titan is destroyed through photochemical reactions at a rate of $2.5 \times 10^{-14} \mathrm{~mol} \mathrm{~cm}^{-2} \mathrm{~s}^{-1}$ (Yung et al., 1984). If Titan's atmosphere is in steady state, this loss could be supported by methane produced by serpentinization of silicates in the presence of carbonate-bearing fluids at a rate of $\sim 3.2 \times 10^{12} \mathrm{~kg}$ of silicate consumed per year. If this rate is typical of the history of Titan, it would lead to time-integrated hydration of a $\sim 39 \mathrm{~km}$-thick layer of reactant rock. Similarly, the methane on Pluto is hydro-dynamically escaping with a flux of 2.2 10.1 $\times 10^{-14} \mathrm{~mol} \mathrm{~cm}^{-2} \mathrm{~s}^{-1}$ (Trafton et al., 1997). This flux could have been supported throughout the history of Pluto by gradual aqueous alteration of a 34 to $157 \mathrm{~km}$-thick global layer of reactant silicate rock. In both cases, the layer of reactant rock could be several times thinner if it is rich in metallic iron (because metallic iron is a more efficient source of $\mathrm{H}_{2}$ during aqueous alteration than $\mathrm{Fe}^{(\mathrm{II})}$-silicates; Zolotov and Shock, 2004; Oze and Sharma, 2005).

\section{ACKNOWLEDGEMENTS}

This research was supported by a grant to J.M.E. from the NASA Cosmochemistry Program. We thank Sara Russell for her editorial handling of this manuscript, and Chris Romanek and two anonymous reviewers for thoughtful and constructive comments.

\section{REFERENCES}

Affek H. P. and Eiler J. M. (2006). Abundance of mass $47 \mathrm{CO}_{2}$ in urban air, car exhaust, and human breath. Geochim. Cosmochim. Acta 70: 1-12. 
Al-Aasm I. S., Taylor B. E. and South B. (1990). Stable isotope analysis of multiple carbonate samples using selective acid extraction. Chem. Geol. 80: 119-25.

Atreya S. K., Adams E. Y., Niemann H. B., Demick-Montelara J. E., Owen T. C., Fulchignoni M., Ferri F. and Wilson E. H. (2006). Titan's methane cycle. Planet. Space Sci. 54: 1177-1187.

Baker L., Franchi I. A., Wright I. P. and Pillinger C. T. (2002). The oxygen isotopic composition of water from Tagish Lake: Its relationship to low-temperature phases and to other carbonaceous chondrites. Meteorit. Planet. Sci. 37: 977-985.

Benedix G. K., Leshin L. A., Farquhar J., Jackson T. and Thiemens M. H. (2003). Carbonates in CM2 chondrites: Constraints on alteration conditions from oxygen isotopic compositions and petrographic observations. Geochim. Cosmochim. Acta 67: $1577-1588$

Bethke C. M. (1996). Geochemical Reaction Modeling: Concepts and Applications. Oxford University Press.

Brearley A. J. and Jones R. H. (1998). Chondritic meteorites. In Planetary Materials. 3-1 to $3-398$.

Brearley A. J., Saxton J. M., Lyon I. C. and Turner G. (1999). Carbonates in the Murchison CM chondrite: CL characteristics and oxygen isotopic compositions. $30^{\text {th }}$ Lun. and Planet. Sci. Conf. Abstract \#1301.

Browning L. and Bourcier W. (1998). Constraints on the anhydrous precursor mineralogy of fine-grained materials in CM carbonaceous chondrites. Meteorit. Planet. Sci. 33: $1213-1220$.

Browning L. B., McSween H. Y. and Zolensky M. E. (1996). Correlated alteration effects in CM carbonaceous chondrites. Geochim. Cosmochim. Acta 60: 2621-2633.

Clark I. D. and Lauriol B. (1992). Kinetic enrichment of stable isotopes in cryogenic calcites. Chem. Geol. 102: 217-228.

Clayton R. N. and Mayeda T. K. (1984). The oxygen isotope record in Murchison and other carbonaceous chondrites. Earth Planet. Sci. Lett. 67: 151-161.

Clayton R. N. and Mayeda T. K. (1999). Oxygen isotope studies of carbonaceous chondrites. Geochim. Cosmochim. Acta 63: 2089-2104. 
Cruikshank D. P., Roush T. L., Owen T. C., Geballe T. R., Debergh C., Schmitt B., Brown R. H. and Bartholomew M. J. (1993). Ices on the surface of Triton. Science 261: 742-745.

Eiler J. M. and Kitchen N. (2004). Hydrogen isotope evidence for the origin and evolution of the carbonaceous chondrites. Geochim. Cosmochim. Acta 68: 13951411

Eiler J. M. and Schauble E. A. (2004). ${ }^{18} \mathrm{O}^{13} \mathrm{C}^{16} \mathrm{O}$ in Earth's atmosphere. Geochim. Cosmochim. Acta 68: 4767-4777.

Endress M., Zinner E. and Bischoff A. (1996). Early aqueous activity on primitive meteorite parent bodies. Nature 379: 701-703.

Foustoukos D. I. and Seyfried W. E. (2004). Hydrocarbons in hydrothermal vent fluids: The role of chromium-bearing catalysts. Science 304: 1002-1005.

Ghosh P., Adkins J., Affek H. P., Balta B., Guo W., Schauble E. A., Schrag D. and Eiler J. M. (2006). ${ }^{13} \mathrm{C}-{ }^{18} \mathrm{O}$ bonds in carbonate minerals: A new kind of paleothermometer. Geochim. Cosmochim. Acta 70: 1439-1456.

Ghosh P., Eiler J., Campana S. E. and Feeney R. F. (2007). Calibration of the carbonate 'clumped isotope' paleothermometer for otoliths. Geochim. Cosmochim. Acta 71: 2736-2744.

Grady M. M., Wright I. P., Swart P. K. and Pillinger C. T. (1988). The carbon and oxygen isotopic composition of meteoritic carbonates. Geochim. Cosmochim. Acta 52: 2855-2866.

Grasset O. and Pargamin J. (2005). The ammonia-water system at high pressures: Implications for the methane of Titan. Planet. Space Sci. 53: 371-384.

Hoppe P., Amari S., Zinner E. and Lewis R. S. (1995). Isotopic compositions of C, N, O, $\mathrm{Mg}$, and Si, trace element abundances, and morphologies of single circumstellar graphite grains in four density fractions from the Murchison meteorite. Geochim. Cosmochim. Acta. 59: 4029-56.

Horita J. (2001). Carbon isotope exchange in the system $\mathrm{CO}_{2}-\mathrm{CH}_{4}$ at elevated temperatures. Geochim. Cosmochim. Acta 65: 1907-1919.

Horita J. and Berndt M. E. (1999). Abiogenic methane formation and isotopic fractionation under hydrothermal conditions. Science 285: 1055-1057. 
Hummel W., Berner U., Curti E., Pearson F. J. and T T. (2002). Nagra/PSI Chemical Thermodynamic Data Base 01/01. Universal Publishers.

Johnson J. W., Oelkers E. H. and Helgeson H. C. (1992). SUPCRT92 - A software package for calculating the standard molal thermodynamic properties of minerals, gases, aqueous species, and reactions from 1-bar to 5000 bar and $0^{\circ} \mathrm{C}$ to $1000^{\circ} \mathrm{C}$. Comput. Geosci. 18: 899-947.

Keil K. (2000). Thermal alteration of asteroids: evidence from meteorites. Planet. Space Sci. 48: 887-903.

Kim S. T. and O'Neil J. R. (1997). Equilibrium and nonequilibrium oxygen isotope effects in synthetic carbonates. Geochim. Cosmochim. Acta 61: 3461-3475.

Knauth L. P., Brilli M. and Klonowski S. (2003). Isotope geochemistry of caliche developed on basalt. Geochim. Cosmochim. Acta 67: 185-195.

Kulik D. A., Aja S. U., Sinitsyn V. A. and Wood S. A. (2000). Acid-base surface chemistry and sorption of some lanthanides on $\mathrm{K}^{+}$-saturated marblehead illite: II. A multisite-surface complexation modeling. Geochim. Cosmochim. Acta 64: 195213.

Martin B. and Fyfe W. S. (1970). Experimental and theoretical observations on the kinetics of hydration reactions with particular reference to serpentinization. Chem. Geol. 6: 185-202.

McSween H. Y., Ghosh A., Grimm R. E., Wilson L. and Young E. (2002). Thermal evolution models of asteroids. In Asteroids III, The University of Arizona Press. $559-571$.

Neal C. and Stanger G. (1983). Hydrogen generation from mantle source rocks in Oman. Earth Planet. Sci. Lett. 66: 315-20.

Niemann H. B., Atreya S. K., Bauer S. J., Carignan G. R., Demick J. E., Frost R. L., Gautier D., Haberman J. A., Harpold D. N., Hunten D. M., Israel G., Lunine J. I., Kasprzak W. T., Owen T. C., Paulkovich M., Raulin F., Raaen E. and Way S. H. (2005). The abundances of constituents of Titan's atmosphere from the GCMS instrument on the Huygens probe. Nature 438: 779-784. 
Owen T. C., Roush T. L., Cruikshank D. P., Elliot J. L., Young L. A., Debergh C., Schmitt B., Geballe T. R., Brown R. H. and Bartholomew M. J. (1993). Surface ices and the atmospheric composition of Pluto. Science 261: 745-748.

Oze C. and Sharma M. (2005). Have olivine, will gas: Serpentinization and the abiogenic production of methane on Mars. Geophys. Res. Lett. 32: L10203/1-L10203/4.

Palmer D. A. and Drummond S. E. (1986). Thermal decarboxylation of acetate. Part I. The kinetics and mechanism of reaction in aqueous solution. Geochim. Cosmochim. Acta. 50: 813-23.

Proskurowski G., Lilley M. D., Kelley D. S. and Olson E. J. (2006). Low temperature volatile production at the Lost City Hydrothermal Field, evidence from a hydrogen stable isotope geothermometer. Chem. Geol. 229: 331-343.

Riciputi L. R., McSween H. Y., Johnson C. A. and Prinz M. (1994). Minor and traceelement concentrations in carbonates of carbonaceous chondrites, and implications for the compositions of coexisting fluids. Geochim. Cosmochim. Acta 58: 1343-1351.

Rosenberg N. D., Browning L. and Bourcier W. L. (2001). Modeling aqueous alteration of CM carbonaceous chondrites. Meteorit. Planet. Sci. 36: 239-244.

Rubinson M. and Clayton R. N. (1969). Carbon-13 fractionation between aragonite and calcite. Geochim. Cosmochim. Acta 33: 997-1002.

Santrock J., Studley S. A. and Hayes J. M. (1985). Isotopic analyses based on the mass spectrum of carbon dioxide. Anal. Chem. 57: 1444-1448.

Schauble E. A., Ghosh P. and Eiler J. M. (2006). Preferential formation of ${ }^{13} \mathrm{C}-{ }^{18} \mathrm{O}$ bonds in carbonate minerals, estimated using first-principles lattice dynamics. Geochim. Cosmochim. Acta 70: 2510-2529.

Sephton M. A. and Gilmour I. (2001). Compound-specific isotope analysis of the organic constituents in carbonaceous chondrites. Mass Spectrom. Rev. 20: 111-120.

Sheppard S. M. F. and Gilg H. A. (1996). Stable isotope geochemistry of clay minerals. Clay Mineral. 31: 1-24.

Shock E. L. (1988). Organic-acid metastability in sedimentary basins. Geology 16: 886890. 
Stevens T. O. and McKinley J. P. (1995). Lithoautotrophic microbial ecosystems in deep basalt aquifers. Science. 270: 450-454.

Stevens T. O. and McKinley J. P. (2000). Abiotic controls on $\mathrm{H}_{2}$ production from basaltwater reactions and implications for aquifer biogeochemistry. Environ. Sci. Technol. 34: 826-831.

Stiller M., Rounick J. S. and Shasha S. (1985). Extreme carbon-isotope enrichments in evaporating brines. Nature 316: 434-435.

Tobie G., Lunine J. I. and Sotin C. (2006). Episodic outgassing as the origin of atmospheric methane on Titan. Nature 440: 61-64.

Trafton L. M., Hunten D. M., Zahnle K. J. and McNutt R. L. J. (1997). Escape processes at Pluto and Charon In Pluto and Charon, The Uiversity of Arizona Press. 475522 .

Tyra M. A., Farquhar J., Wing B. A., Benedix G. K., Jull A. J. T., Jackson T. and Thiemens M. H. (2007). Terrestrial alteration of carbonate in a suite of Antarctic CM chondrites: Evidence from oxygen and carbon isotopes. Geochim. Cosmochim. Acta. 71: 782-795.

Wenner D. B. and Taylor H. P. (1971). Temperatures of serpentinization of ultramafic rocks based on ${ }^{18} \mathrm{O} /{ }^{16} \mathrm{O}$ fractionation between coexisting serpentine and magnetite. Contrib. Mineral. Petrol. 32: 165-185.

Wilson L., Keil K., Browning L. B., Krot A. N. and Bourcier W. (1999). Early aqueous alteration, explosive disruption, and reprocessing of asteroids. Meteorit. Planet. Sci. 34: 541-557.

Yang J. M. and Epstein S. (1984). Relic interstellar grains in Murchison meteorite. Nature 311: 544-547.

Young E. D. (2001). The hydrology of carbonaceous chondrite parent bodies and the evolution of planet progenitors. Phil. Trans. R. Soc. Lond. A 359: 2095-2109.

Yung Y. L., Allen M. and Pinto J. P. (1984). Photochemistry of the atmosphere of Titan: Comparison between model and observations. Astrophys. J. Suppl. Ser. 55: 465506. 
Zolensky M., Bodnar R., Tsuchiyama A., Okudaira K., Noguchi T., Uesugi K. and Nakano T. (2004). Fluid inclusions in chondrites. Meteorit. Planet. Sci. 39: A118A118.

Zolensky M. E. (1984). Hydrothermal alteration of CM carbonaceous chondrites: Implications of the identification of tochilinite as one type of meteoritic PCP. Meteoritics 19: 346-347.

Zolotov M. Y. and Shock E. L. (2004). Pathways of hydrogen generation during aqueous alteration of chondrites. Meteorit. Planet. Sci. 39: A119-A119. 